Arab Univ. J. Agric. Sci., Ain Shams Univ., Cairo, Egypt

27(2), 1513-1527, 2019

Website: http://ajs.journals.ekb.eg

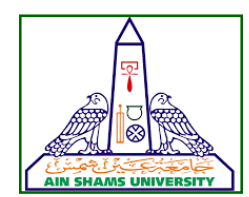

1513

\title{
EFFECT OF GRINDING AND PARTICLE SIZE ON SOME PHYSICAL AND RHEOLOGICAL PROPERTIES OF CHITOSAN
}

\author{
Ibrahim $^{1,{ }^{\star}}$ A.I., Ebeid ${ }^{1}$ H.M., Kishk ${ }^{1}$ Y.F.M., Abdel Fattah ${ }^{1}$ A.A. \\ and Mahmoud ${ }^{2}$ K.F. \\ 1- Food Sci. Dept., Fac. of Agric., Ain Shams Univ., P.O. Box 68, Hadayek Shoubra 11241, \\ Cairo, Egypt \\ 2- Food Technology Dept., National Research Centere, Dokki, Giza, Egypt \\ ${ }^{*}$ Corresponding author: ibrahim_amin89@agr.asu.edu.eg
}

Received 26 May, 2019

Accepted 2 July, 2019

\begin{abstract}
The present study was conducted to prepare nano-chitosan particles $(\mathrm{CN})$ by ultrafine grinding from crude chitosan powder (CC) using a ball mill with 130 numbers of zirconia beads in range from 0.5 to $1.5 \mathrm{~mm}$ diameter (75 beads $0.5 \mathrm{~mm}$ diameter, 30 beads $1.0 \mathrm{~mm}$ diameter and 25 beads 1.5 $\mathrm{mm}$ diameter). In addition, physical and rheological properties of chitosan solutions were determined. The results revealed that ultrafine grinding has effectively milled the chitosan particles to nanoscale. Prepared chitosan nanoparticles were characterized by devices X-Ray Diffraction (XRD), Zetasizer particle sizes and Zeta potential of chitosan particles (after milling for 30, 60 and 90 minutes). The particle size of nano-chitosan was distributed in a range of $250-600 \mathrm{~nm}$. with a polydispersity index $<1$. The particle electric charge was increased to the level of +24 to $+33 \mathrm{mV}$. X-ray diffractogramms showed lower intensity and a shift in the peak to the lower $2^{\circ} \theta$ angle due to the charge in particles cristllinity. The rheological parameters from power law at $25{ }^{\circ} \mathrm{C}$ were obtained using a rotational coaxial viscometer. The flow behavior index $(n)$ of the different tested chitosan solutions were less than 1.0 (ranging between 0.36-0.74) indicating their pseudoplastic. The higher value of consistency coefficient $(K)$ was recorded for $\mathrm{CN} 30$ at $\mathrm{pH} 3$ and lower $(\mathrm{n})$ values than those of crude chitosan at $\mathrm{pH}$ 7. Generally, the results showed that the studied polymer solutions exhibited non-Newtonian behavior with shear-thinning. The results indicate the possibility of safe using nanoparticles of chitosan in food applications as a result of increased efficiency and
\end{abstract}

use as an anti-oxidant and antimicrobial with reducing the amount used to deliver the desired purpose. Additional research is required to further investigate the potential value-added utilization of these chitosan derivatives in improving the quality and safety of some food products.

Keywords: nano-chitosan, wet ball mill, nanotechnology, Physical and rheological properties.

\section{INTRODUCTION}

Chitosan, is a carbohydrate polymer structurally resembles cellulose in terms of chemical composition, as both compounds are made by linear $\beta$ $(1,4)$-linked monosaccharides, being glucosamine (GlcN) and N-acetlyl-D-glucosamine (GlcNAc). However, the ones present in chitosan are at different ratios, Kumar (2000). Chitosan is generally recognized as Safe (GRAS) by the US FDA, (2001). It can be derived from crustacean seafood wastes such as shells of crabs, shrimps and crawfish, (Rhazi et al 2004).

A number of researchers demonstrated that chitosan is a natural and had a great potential for a wide range of uses due to its biodegradability, biocompatibility, non-toxicity polysaccharide, low cost, and friendly material with unique physicochemical properties. The applications of chitosan covers a variety of fields, such as pharmaceutical and medical applications, paper production, textiles, waste water treatment, biotechnology, cosmetics, food processing, and agriculture (Li et al 1992).

According to Mao et al (2004), the solubility of chitosan increased with decreasing molecular weight. To enhance the functionality, several chi- 
tosan derivatives have been developed and studied in current and novel applications. Some of these new derivatives include the carboxymethyl chitosan, which has increased solubility and trimethyl chitosan which is already used for gene delivery, and Ndodecylated chitosan (chitosan-12), which has enhances thermal stability (Badawy and Rabea, 2011). Chang et al (2015). reported that at neutral $\mathrm{pH}$, chitosan activity increased as the molecular weights decreased and little activity was observed for chitosan's with molecular weights $>29.2 \mathrm{kDa}$. At pH 5.0 and 6.0, chitosan's exhibited good water solubility and zeta potential decreased with the molecular weights, whereas the solubility and zeta potential of the chitosan's decreased with increasing molecular weights at $\mathrm{pH} 7.0$.

Due to their small size, nanomaterial's show different physical, chemical, and biological properties compared to their corresponding bulk materials, (Daniel and Astruc, 2004). Several methods have been developed to produce chitosan nanoparticles for example, emulsification and crosslinking, emulsion droplet coalescence, emulsion solvent diffusion, ionic gelation with tripolyphosphoric anions and Polyelectrolyte complexation, modified ionic gelation with radical polymerization and desolvation as well as by dry and wet milling. (pour et al (2011); Grenha (2012); Zhang et al (2012) and (2013), as well as Fathi et al 2014).

Chitosan nanoparticles have smaller size than bulk chitosan and this property could make it unique. Nano-chitosan is a natural material with antibacterial effects (Qi et al 2004 and De Paz et al 2011). According to Zhang et al (2006 and 2013), nano-chitosan particles forms micelles in water with an average particles diameters ranging from 36 to $218 \mathrm{~nm}$, which could be approved by using FT-IR, HNMR and X-ray diffraction spectrometry. The hypolipidemic activities of high and low molecular weights of chitosan nanopowders prepared by ultrafine milling were evaluated in rats. The results showed that the hypolipidemic activity of chitosan nanopowder was better than ordinary chitosan, and LMW-chitosan-NP was superior to HMW-chitosan-NP in hypolipidimic activity.

The antibacterial effect of chitosan nanoparticles on Streptococcus mutans, Escherichia coli and Staphylococcus aureus were approved by $\mathrm{Ma}$ et al 2010, De Paz et al 2011 and Sun et al 2017 as well as Ma et al 2017). Sozer and Kokini (2009) as well as Alishahi (2014) reported that chitosan nanoparticles showed high potential to be used as potent antibacterial agent over prolonged time, especially when chitosan nanoparticle loaded with nisin because it is safe and effective nature as natural antibacterial. The application of nano-chitosan as antibacterial agent on food was investigated by a verify of researches. Bangun et al (2018), applied chitosan -tripolyphosphat nanoparticles as antibacterial against Staphylococcus aureus and Pseudomonas aeruginosa and found that this material give the highest and bacterial affectivity against microorganisms.

Chitosan nanoparticles has also found wide application in food and drugs as encapsulating agent (Sozer and Kokini, 2009). On other side, Hosseini et al (2013) applied two step method for encapsulation of oregano essential oil in chitosan nanoparticles. The obtained nanoparticles exhibited regular distribution and their spherical shape size was $40-80 \mathrm{~nm}$.

Stoica et al (2013) applied chitosantripolyphosphate nanoparticles for the encapsulation of polyphenols extracted from rose hubs, while Zhang et al (2015), as well as Liu et al (2015) evaluated poly phenol-Zn complex loaded Beta chitosan nanoparticles and found that the average size was 84-55 $\mathrm{nm}$ and the complex exhibited higher antioxidant activity than that of the free poly phenols.

Chitosan nanoparticles were also used for the immobilization of invertase enzyme, (Valerio et al 2013) as supplement for yogurt to reduce cholesterol with no significantly adverse effect on the quality attributes of yogurt (Seo et al 2009).

Chitosan nanoparticles have been applied as adsorbing agent of food dyes from aqueous solution (Zhou et al 2014). Further applications of nano-chitosan were found also in pharmaceutical and medical sector (Grenha, A. 2012 and Dounighi et al 2012).

Chitosan when dissolved in acidic solution forms hydrogels and gives viscous solutions. The viscosity and viscoelastic properties determines the extent of penetration of chitosan into the fabric structure (Sano et al 1999 and Torres et al 2006). By reducing the particle size to nano level, the intrinsic viscosity of chitosan solution is lowered significantly, but the storage stability was affected adversely.

The purpose of this work was focused on the preparation and characterization of chitosan nanoparticles prepared by wet milling method and study the rheological properties of the chitosan nanoparticles under different $\mathrm{pH}$ - levels and particles size. 


\section{MATERIALS AND METHODS}

Materials: Chitosan, low molecular weight (CC) with $>75 \%$ deacetylation extracted from shrimp shells, was purchased from Sigma-Aldrich, company Saint Louis, United State of America (USA). Boric acid, borax, citric acid, dibasic sodium phosphate, phosphate buffer, and sodium acetate trihydrate were purchased from El Nasr Pharmaceutical Chemicals Company, Cairo, Egypt.

Preparation of chitosan nanoparticles: Conventional particle size reduction techniques such as ball milling process (Ball milling Model: PQ-N2 Planetary Ball Mill, Gear Drive 4- station - planetary Ball mill, $220 \mathrm{v}$ ) was used for preparation of chitosan nanoparticles (CN) of $\mathrm{CC}$ according to Inkyo et al (2006) and Joni et al (2015). A $25 \mathrm{~g}$ weight of chitosan powder was ball milled in a 200 $\mathrm{ml}$ agate vessel with 130 numbers of zirconia beads in range from 0.5 to $1.5 \mathrm{~mm}$ diameter $(75$ beads $0.5 \mathrm{~mm}$ diameter, 30 beads $1.0 \mathrm{~mm}$ diameter and 25 beads $1.5 \mathrm{~mm}$ diameter) and milling at $4000 \mathrm{rpm}$ in a high energy planetary ball mill was performed. Different samples were prepared by varying the milling duration, and then the dried chitosan powder was pulverized for 30,60 and 90 min to obtain fine powder. A Ball milling process was used as a dispersing agent to prevent particles agglomeration. Table (1) shows the experimental conditions in detail. The obtained powder was selected to obtain more uniform nano size.

Table 1. Experimental condition for the preparation of chitosan nanoparticles and Particle size range

\begin{tabular}{|c|c|c|c|}
\hline Sample & $\begin{array}{c}\text { Rotational } \\
\text { speed } \\
\text { (rpm)* }\end{array}$ & $\begin{array}{l}\text { Milling } \\
\text { Time } \\
\text { (min) }\end{array}$ & $\begin{array}{c}\text { Particle } \\
\text { size range } \\
(\mathrm{nm})\end{array}$ \\
\hline $\begin{array}{l}\text { Chitosan } \\
\text { (CN30) }\end{array}$ & 4000 & 30 & $300-600$ \\
\hline $\begin{array}{l}\text { Chitosan } \\
\text { (CN60) }\end{array}$ & 4000 & 60 & $250-500$ \\
\hline $\begin{array}{l}\text { Chitosan } \\
\text { (CN90) }\end{array}$ & 4000 & 90 & $250-500$ \\
\hline
\end{tabular}

* 4000 rpm: Sun wheel 290 rpm, Planetary vessels 580 rpm, Frequency converter $40 \mathrm{~Hz}$

Steps of the milling Procedure: The dried CC was pulverized by ball mill to obtain fine powder. The bead mill consists of $200 \mathrm{ml}$ vessel, a pump and a mixing tank. The vessel was filled with beads up to $70 \%$ capacity. The slurry was prepared by mixing the chitosan powder and distilled water. The mixed chitosan was stirred using magnetic stirrer for 30 minutes before beads milling. The PEG 400 (Polyethylene glycol) dispersing agent was added after the mixing time of 15 minutes. The slurry of the chitosan was added into the vessel which contained zirconia beads and impeller operated at a speed of $4000 \mathrm{rpm}$. The beads were agitated in the lower portion of the vessel (dispersing section) to break up the aggregate to avoid agglomeration of chitosan nanoparticles in the suspension.

After dispersion, the suspension was pumped from the dispersing section to separation region inside the ball mill where centrifugal force was used to separate the zirconia beads from the particle suspension. The chitosan particle suspension was then recycled back to the dispersing section. In order to keep the temperature of the system constant $\left(25^{\circ} \mathrm{C}\right)$, the vessel was supported by a water jacket system and was completely sealed. The water-suspended chitosan particles with weight fractions of $0.1 \mathrm{wt}$. \%, milling time of 30,60 and 90 minutes and addition acetic acid solution $(1 \%, v / v)$ after milling to promote the positive surface charge were used for optimal technical conditions for beads milling. After milling process, chitosan was freeze-dried (LABCONCO, Kansas City, USA) at $-50^{\circ} \mathrm{C}$ and 0.014 mbar for 2 days to reach moisture content $4 \%$. The obtained powder was selected to obtain more uniform micron size (around $37 \mu \mathrm{m}$ ) by using sieves with mesh 400 and subjected to beads milling process.

Physical Characterization Techniques of chitosan nanoparticles

\section{Analysis by X- Ray powder diffraction (X-RD)}

In order to confirm the crystalline or amorphous nature of chitosan nanoparticles, the dried nano chitosan samples were subjected to X-ray diffraction analysis by using an X-ray diffraction apparatus type PANalytical $X$, pert PRO X-ray machine, Netherland. The X-ray source was cobalt $(\mathrm{Cu} \mathrm{K} \alpha)$ radiation $(\lambda=1.5406 \AA)$, with $40 \mathrm{kV}$ monochromator and $30 \mathrm{~mA}$ power according to the methods of Pooja et al (2014). It is a non - destructive technique widely used. for the characterization of polymer materials. The samples were placed in thin layer on the sample holder where it was subjected to the X-ray beam from the cobalt source. The Xray pattern was recorded in the $2^{\circ} \theta$ range from $4^{\circ}$ to $80^{\circ}$ at a scanning rate of $5^{\circ} \mathrm{min}^{-1}$ and a measuring temperature $25^{\circ} \mathrm{C}$ according to Anand et al 
2014 and 2018. The X-ray strikes the surface of the powder crystals, where it is scattered or absorbed according to the crystallinity degree of the powder particles under testing. The intensities of the scattered X-rays were recorded by a detector and the intensity is given in cps unit (Counts per second) or as cts's (Counts). Crystalline surface will give high intensity value, while amorphous surfaces will give lower intensity values.

Particle Size Measurement and particle size distribution: Nanoparticle sizes and zeta potential of particles of chitosan samples (after treatment at 30, 60 and $90 \mathrm{~min}$ ) were measured using dynamic light scattering (DLS) by Zetasizer (Malvern, Model: Zetasizer nano series (Nano ZS), United Kingdom), at a scattering angle of $173^{\circ} \mathrm{C}$ using laser. The range of size from $0.6: 6000 \mathrm{~nm}$, the zeta potential range from -200:200 mV: each measurement was being the average of 16 runs, each of 10 $\mathrm{s}$ duration. Samples were measured after $5 \mathrm{~min}$ equilibration at $25 \stackrel{\circ}{\circ}$ and results are reported as the average of 3 measurements.

\section{Preparation of Buffers used for dissolvtion of chitosan}

Boric Acid-Borax Buffer: Stock solutions were prepared by dissolving $\mathrm{X}$ : $0.2 \mathrm{M}$ solution of boric acid $(12.4 \mathrm{~g}$ in $1000 \mathrm{ml})$ and $\mathrm{Y}$ : $0.05 \mathrm{M}$ solution of borax $(19.05 \mathrm{~g}$ in $1000 \mathrm{ml}$; $0.2 \mathrm{M}$ in terms of sodium borate) to obtained pH $9200 \mathrm{ml}$ of $X$ were mixed with $236 \mathrm{ml}$ of $Y$. (Stoll and Blanchardy, 2009).

Citrate-phosphate Buffer: Citrate-phosphate Buffer Stock solutions were prepared by dissolving $\mathrm{X}: 0.1 \mathrm{M}$ solution of citric acid $(19.21 \mathrm{~g}$ in $1000 \mathrm{ml})$ and $\mathrm{Y}$ : $0.3 \mathrm{M}$ solution of dibasic sodium phosphate (53.65 g of $\mathrm{Na}_{2} \mathrm{Hpo} 4.7 \mathrm{H}_{2} \mathrm{O}$ in $1000 \mathrm{ml}$ ) to obtained $\mathrm{pH}$ 3. $39.8 \mathrm{ml}$ of $\mathrm{X}$ were mixed with $10.2 \mathrm{ml}$ of $\mathrm{Y}$. $\mathrm{pH}$ 5. $24.3 \mathrm{ml}$ of $X$ were mixed with $25.7 \mathrm{ml}$ of $Y$. $\mathrm{pH} 7$ and for $6.5 \mathrm{ml}$ of $X$ were mixed with $43.6 \mathrm{ml}$ of Y. (Stoll and Blanchardy, 2009).

Viscosity measurements: Viscosity and flow properties for solutions of crude chitosan and their different nanoparticle samples were measured as described by Gladwell et al (1985) at $25{ }^{\circ} \mathrm{C}$ using a rotational coaxial viscometer (Rheotest 2.2, Medingen, Germany) type RV. The tested material was introduced into the "S1" cylinder of the viscometer. In such a case, shear stress was developed at shear rate values ranging from 3.0 to $1312 / \mathrm{sec}$. The dynamic viscosity was calculated according to the following formula: $(n)=\sigma .100 / y \quad(c p)$

Where: $\eta=$ Dynamic viscosity in centi poise $\sigma=$ Shear stress $\left(\right.$ dyne $\left./ \mathrm{cm}^{2}\right) . \quad Y=$ Shear rate $(\mathrm{sec}-1)$. $(\sigma)$ Was calculated from the obtained torque value

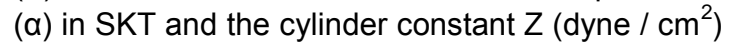
according to the following equation as given by the manufacturer:

$\sigma=\mathbf{Z} \boldsymbol{\alpha}$

The power law parameters (consistency coefficient $(\mathrm{K})$ and flow behavior index (n)) were calculated from the regression analysis of In shear rate and In shear stress data as mentioned by Paredes et al. (1988). The power law equation is as follows:

$\sigma=K \cdot \gamma^{n}$

Chitosan particles were dissolved at $1 \%$ concentration in the prepared buffer solutions to obtain different $\mathrm{pH}$-levels.

\section{RESULTS AND DISSCUSION}

Physical Characterization of chitosan Nanoparticles

X-ray diffraction pattern of Nano-chitosan samples

Earlier researches on X-ray diffraction pattern of crude chitosan with $>75 \%$ deacetylation revealed the presence of 2 peaks at $2^{\circ} \theta=17.2^{\circ}$ and $21^{\circ}$ with intensity of 600 and $1200 \mathrm{cps}$, respectively and indicating high crytallinity degree of crude chitosan (Qi et al 2004; Islam et al 2011 and Anand et al 2018).

The X-ray pattern for the chitosan nanoparticles subjected to different time of ball milling are presented in Fig. (1, A, B and C). After 30 minutes of ball milling, the X-ray diffraction pattern of nanochitosan was totally different than that of crude chitosan. The X-ray diffractogram showed a major peak at $2^{\circ} \theta=20.337^{\circ}$ with an intensity of 350 counts/s, being much lower than that of crude chitosan (600-1200 counts/s). The X-ray diffractogram showed other smaller peaks at $2^{\circ} \theta=11.96^{\circ}$, $26.48^{\circ}$ and $39.78^{\circ}$ but without any physical meaning for the structure of nano-chitosan crystals. The XRD of nano-chitosan is a characteristic of an amorphous polymer. According to Qi et al (2004), chitosan nanoparticles are comprised of a dense network structure of interpenetrating polymer chains crosslinked to each other. The XRD impli- 
Properties of Chitosan

cated grater disarray in chain alignment in the nanoparticles after ball milling for 30 minutes. According to Tang et al (2003) and Yao et al (2018), it appears that the wet milling process induces violent collisions between the milling media which can destroy or disorder the crystal structure. During the grinding period, the high rate of rotation of the zirconium oxide media could bring out massive heat and mechanical shearing force, which probably enhanced lattice vibrations and changed the crystalline state into an amorphous one.

The X-ray diffraction of chitosan samples milled in a ball mill for 60 and 90 minutes are also given in Fig. (1, B and C). After 60 minutes of grinding, the X-ray diffractogram peak was shifted to lower diffractin angle, being 19.86, which is an indication for the change in the amorphous state. The results revealed that extending the milling time to 60 minutes did increase the amorphous phase of the nano-chitosan through shifting the peak to lower diffraction angles and reducing the intensity to the level of $260 \mathrm{cps}$, which indicate increased amorphous structure of the polymer crystal. Further increasing the milling time to $90 \mathrm{~min}$. Fig. $(\mathbf{1}, \mathbf{C})$ resulted in shifting the peak of $\mathrm{X}$-ray diffractogram to higher angle $\left(2^{\circ} \theta=20.37^{\circ}\right)$ without change in the peak intensity (260 counts/s). From these results, it could be concluded that wet milling of crude chitosan in a ball mill for 30 and 60 minutes, resulted in chitosan particles with nano size and increased amorphous structure than those of crude chitosan.

Effect of milling time on particle size, polydispersity and zeta potential of nano-chitosan

Particle size and polydispersity index (PDI) of nano chitosan particles

Particle size is one of the most significant determinant in the intracellular trafficking of the nanoparticles. The uniform particle size distribution is important to enhance their functionality.

The mean size and size distribution of chitosan was analyzed using zeta sizer analysis as mentioned before. Fig. ( 2, A, B and C) shows the size distribution profile of chitosan after different time of milling in mechanical ball mill.

As seen in Fig. (2, A) wet milling of chitosan in ball mill for 30 minutes resulted in reduction of the size of crud chitosan to smaller particles in the nano -size range of 300 to $600 \mathrm{~nm}$ with an average particle size of $411.2 \mathrm{~nm}$. The graph of the particle size showed a narrow distribution with a moderate value of polydisperisity (PDI) 0.939 , which is lower than but higher than the limit of narrow disperisity 0.7 (Qi et al 2004). The results proved that 30 minutes mechanical milling of chitosan are sufficient to reduce the original size to the range of nano-size. It is well known that crude chitosan has arigid crystalline structure through inner- and intra-molecular hydrogen bonding and the shearing and impact forces acting on the crude chitosan molecule during milling process are able to cut the original molecule and reduce their particle size. According to Zhang et al 2012, mechanical shearing force was powerful to break the glucoside bond and resulted in the degradation of carbohydrate. On other side, the used beads in ball mill were of size greater than $0.1 \mathrm{~mm}$, which can produce high impact and shear energy sufficient to disintegrate the original chitosan molecules better than those produced by smaller size of beads (Inkyo et al 2006). Fig. (2, B and C) show the particle size distribution of nano-chitosan particles after 60 and 90 minutes of milling. As seen, extending the milling time to 60 minutes did not enhance the poly-dispersity index of chitosan $(P D I=1)$, but the range of the obtained particles was narrowed to $250-500 \mathrm{~nm}$ and the average particle size was slightly reduced to the level of $376.2 \mathrm{~nm}$. Similar effect was obtained, when the milling time was further extended to 90 minutes Fig. (2, C). The PDI was still at the limit of narrow distribution (1.00) and the particle size range was unchanged in the level of $250-500 \mathrm{~nm}$, but the average particle size was slightly reduced to the level of $369.1 \mathrm{~nm}$. The obtained results agree with those of Inkyo et al 2006 and Rochina et al 2017. They applied mechanical bead milling for preparation of nano-chitosan. They obtained nanoparticles of chitosan in the range from $94.5 \mathrm{~nm}$ to $543.8 \mathrm{~nm}$, which agree to grate extent with the result of the present work. The variation in the obtained particle size was found to be depending on: size of used beads; initial molecular weight of used crude chitosan and the applied $\mathrm{pH}$ during milling process. Beads of diameter bigger than $100 \mu \mathrm{m}(>0.1 \mathrm{~mm})$ as well as medium and high molecular weight of crude chitosan produces nano-chitosan particle with particle size greater than $200 \mathrm{~nm}$ due to the reagglomeration and the dominance of the Van der Waals forces between the particles, which increase the average particle size of nanoparticles. Optimizing the $\mathrm{pH}$ value of the dispersion during milling is necessary to reduce the polydispersity index from 0.932 to the pattern of narrow distribution with PDI $<0.7$. 

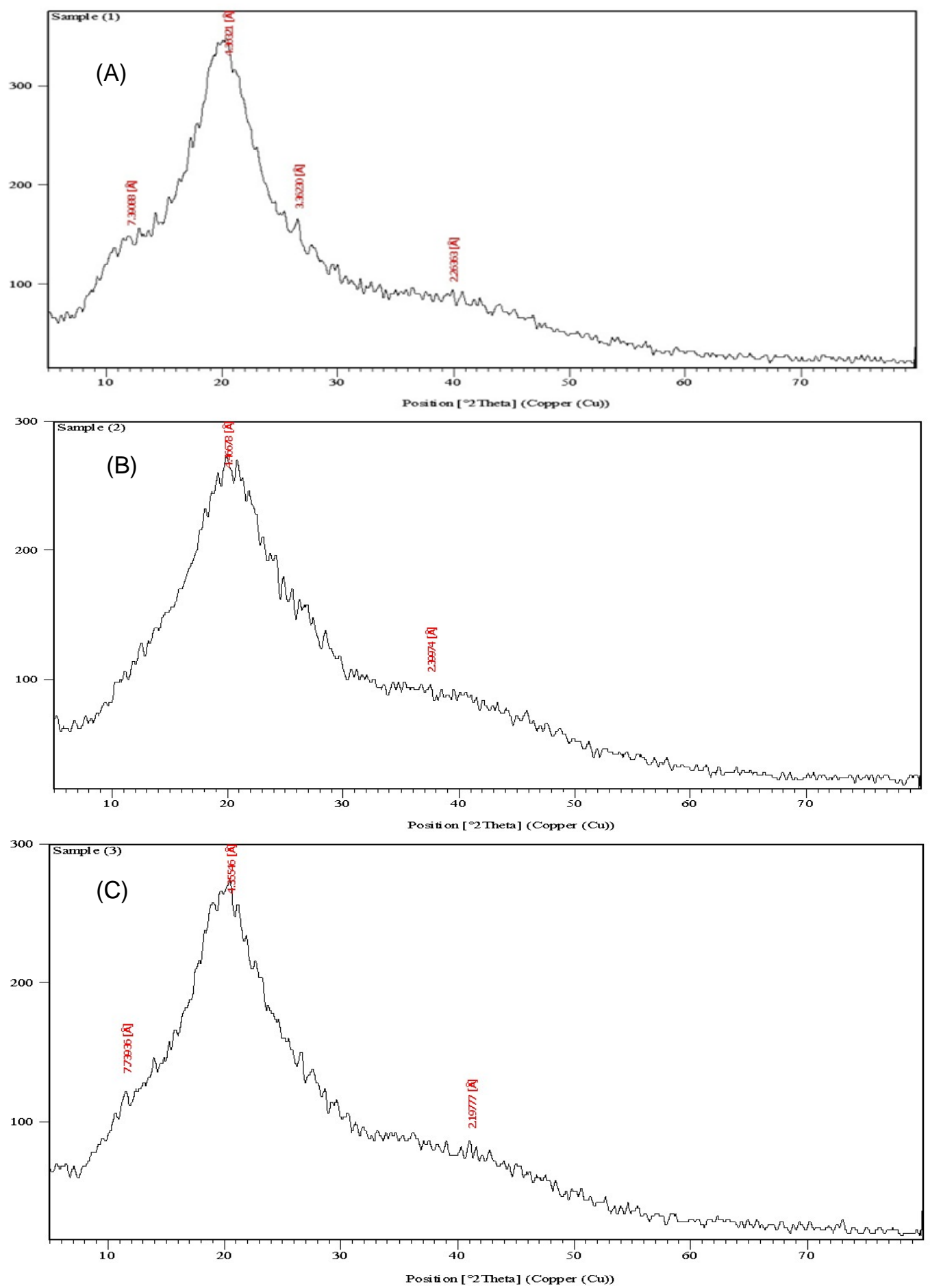

Fig. 1. The X-ray diffraction (XRD) pattern of the chitosan after milling process. (A): after 30 min milling process, (B): after 60 min milling process, (C): after 90 min milling process. 
Size Distribution by Number

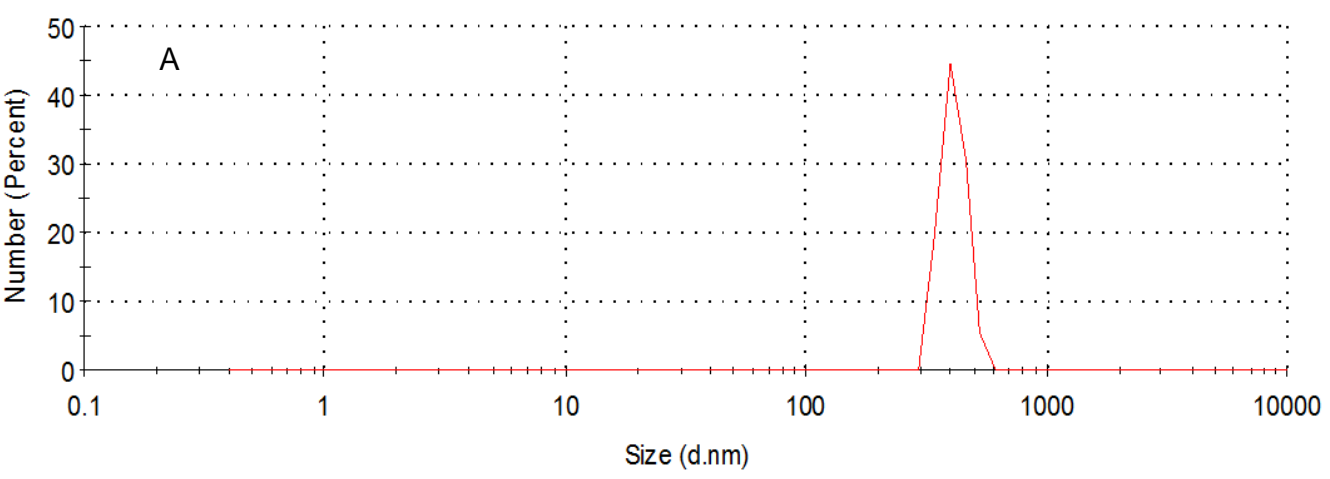

Size Distribution by Number

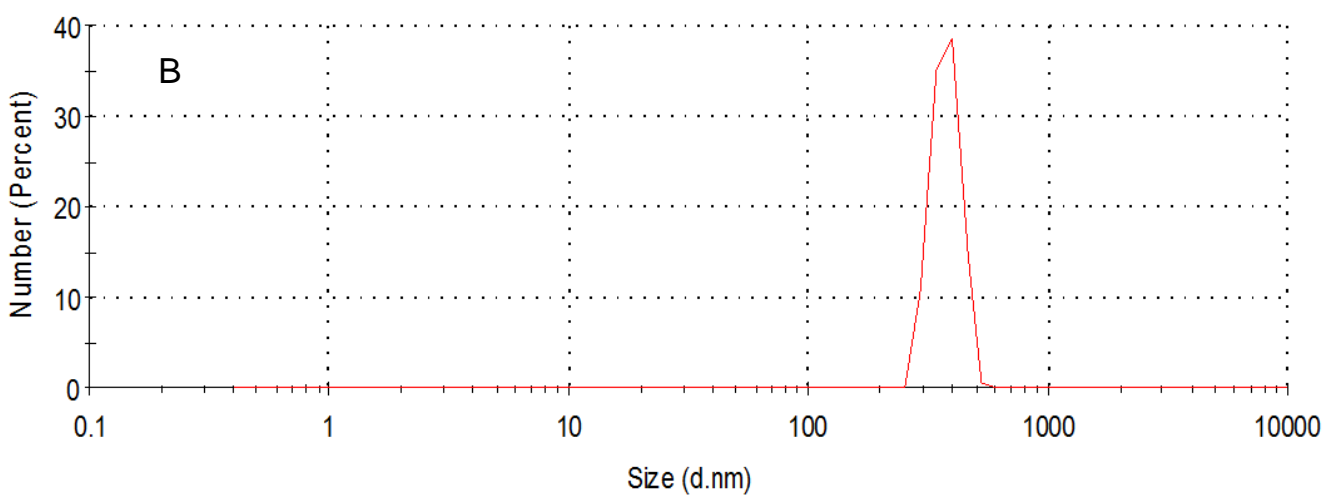

Size Distribution by Number

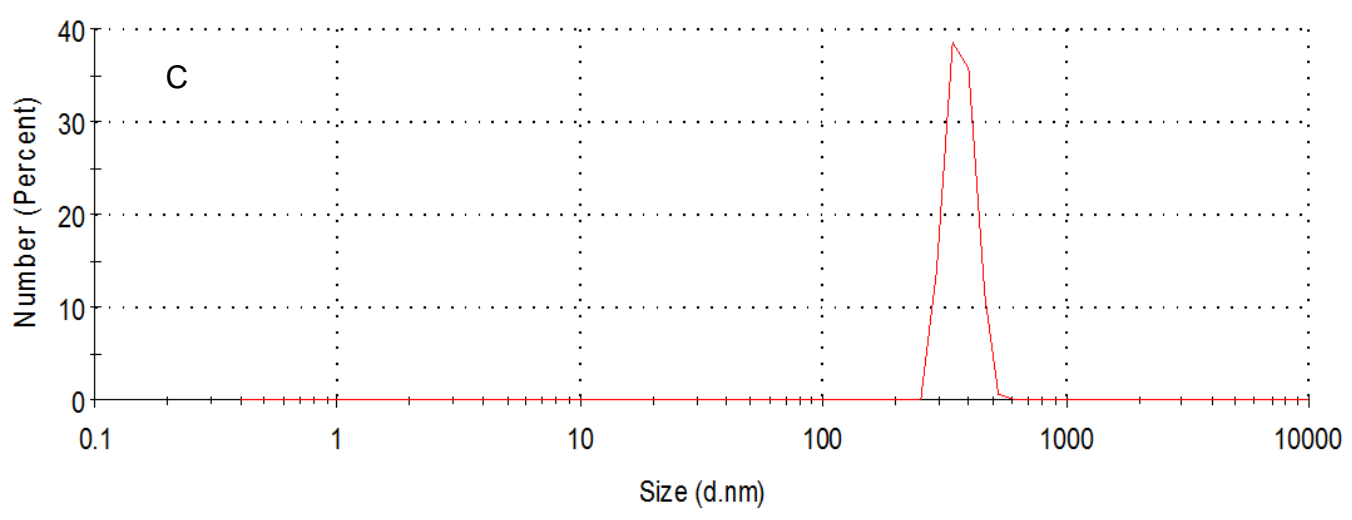

Fig. 2. Particle size distribution of chitosan

(A): after 30 min milling process $\mathrm{PDI}=0.939$ and Particle size $=411.2 \mathrm{~nm}$

(B): after 60 min milling process $P D I=1.000$ and Particle size $=376.2 \mathrm{~nm}$

(C): after 90 min milling process $P D I=1.000$ and Particle size $=369.1 \mathrm{~nm}$ 
Nano particles with small diameters $(60: 200)$ $\mathrm{nm}$ could be obtained by chemical methods using tripolyphosphate solutions to break the chitosan molecule ( $\mathbf{L i}$ Du et al 2009 and Rampion et al 2013).

\section{Zeta potential of chitosan nanoparticles}

Zeta potential, beside size distribution, are essential characteristic parameters for nano suspensions. Zeta potential is the surface charge which can greatly influence particle stability in suspensions through the electrostatic repulsion between adjacent, similarly charged particles in dispersion. For small enough molecules or particles, a high zeta potential will confer stability, i.e., the solution or dispersion will resist to aggregation. Fig. (3, A, B and C) demonstrate the zeta potentials of chitosan nanoparticles after 30,60 and 90 minutes of milling. As seen in Fig.3 A, the zeta potentials of the chitosan nanoparticles, after $30 \mathrm{~min}$ process, was in the range of $10-40 \mathrm{mV}$ with an average charge of $+24.4 \mathrm{mV}$. Chitosan molecules are likely to adopt a dense conformation in the solution because of electrostatic repulsion force existing between amine groups along the molecular chain. Therefore, it could be expected that still be a high proportion of $\mathrm{NH}_{2}$ groups on the chitosan chain which remains unoccupied (Esquivel et al 2015). Fig. $(3$, B) show the zeta potential of chitosan nanoparticles after 60 minutes of milling. As seen, the particle charge was slightly changed to an average of $+27.8 \mathrm{mV}$, while in Fig. $(3, \mathbf{C})$, the zeta potential of chitosan nanoparticles after 90 minutes milling was further increased to an average charge of +33 $\mathrm{mV}$. The obtained results agree with those of $\mathbf{~ i ~} \mathbf{D u}$ et al 2009; Rochima et al 2017 and Yao et al 2018. They mentioned that a suspension with an absolute zeta potential higher than $30 \mathrm{mV}$ implicated stable system solely stabilized by electrostatic repulsion and they obtained zeta potential values for chitosan nanoparticles of range 25 to 31.8 $\mathrm{mV}$. However, the electric charge of the particles depends also on the $\mathrm{pH}$ of the chitosan suspension and decreasing the $\mathrm{pH}$ increases the positive charge leading to electrostatic stabilization in chitosan suspension. Chitosan nanoparticles are commonly used as antibacterial agent. Therefore, Duhani et al 2010 stated that zeta potential can also determine nanoparticle interaction in vivo with the cell membrane of bacteria, which is usually negatively charged. Based on the zetpoteantial values obtained in the present work, it could be concluded that suspension of chitosan nanoparticles will be stable.

\section{Rheological properties of chitosan solutions}

Chitosan solutions (1\%) suspended in a different conditions of $\mathrm{pH}$ values (3, 5, 7 and 9) were subjected to rheological analysis using a rotational viscometer. The suspension were tested in the shear rate between $27 \mathrm{~S}^{-1}$ to $1312 \mathrm{~S}^{-1}$ and the corresponding torque data were converted to shear stress values and the results are given in Table (2) Figs. (4, 5, 6 and 7) represent the flow curves of chitosan solutions obtained by plotting the shear stress value versus shear rate data. As seen, the obtained flow curves were not exactly linear and showed a slight deviation from the pattern of Newtonian fluids and therefore they could be analyzed using power law equation for non- Newtonian fluids. As seen, the solubility of chitosan at $\mathrm{pH} 3$ was complete. The chitosan particles were totally hydrated and their coil volume was increased by the surrounding water molecules which led to increased viscosity of the chitosan solution. As seen in Fig. (4), the maximum shear stress of the different tested chitosan solutions was in the range of 80-270 Dynes $/ \mathrm{cm}^{2}$, which was higher than those obtained at other $\mathrm{pH}$ values. The effect of particle size and milling time was very obvious. As seen in Fig. (4), the maximum shear stress of the crude chitosan solutions at $\mathrm{pH} 3$ and shear rate $1312 \mathrm{~S}^{-1}$ was 170 Dynes $/ \mathrm{cm}^{2}$. Milling chitosan particles for $30 \mathrm{~min}$ in a ball mill resulted in higher viscosity values of the obtained solution. The maximum shear stress of the nano chitosan particles obtained by 30 min milling was 270 Dynes $/ \mathrm{cm}^{2}$ being $64 \%$ higher than those of crude chitosan. The obtained results agree with those of Zhang et al (2012), who reported that the apparent viscosity of chitosan increased after the milling treatment.

The increase in nano-chitosan viscosity could be referred to the increasing number of coils obtained through size reduction of the crude chitosan molecules, increasing the specific surface area for the same weight chitosan and hence, increasing adsorption and absorption of water molecules on the new formed surfaces leading to increased viscosity. Form the pattern of flow curves in Fig. (4), it seems that increasing the milling time of crude chitosan to 60 and 90 minutes didn't contribute to the forming of new surfaces but it probably led to agglomeration of the nano surfaces to greater particles. This assumption is based on the fact that the flow curves of 60 and 90 minutes milling were lower than those of 30 minutes milling. Therefore, it could be assumed that 30 minutes milling of crude chitosan in a ball mill could be considered as sufficient time to form new surfaces and decrease the particle size to the nano range. 
Zeta Potential Distribution
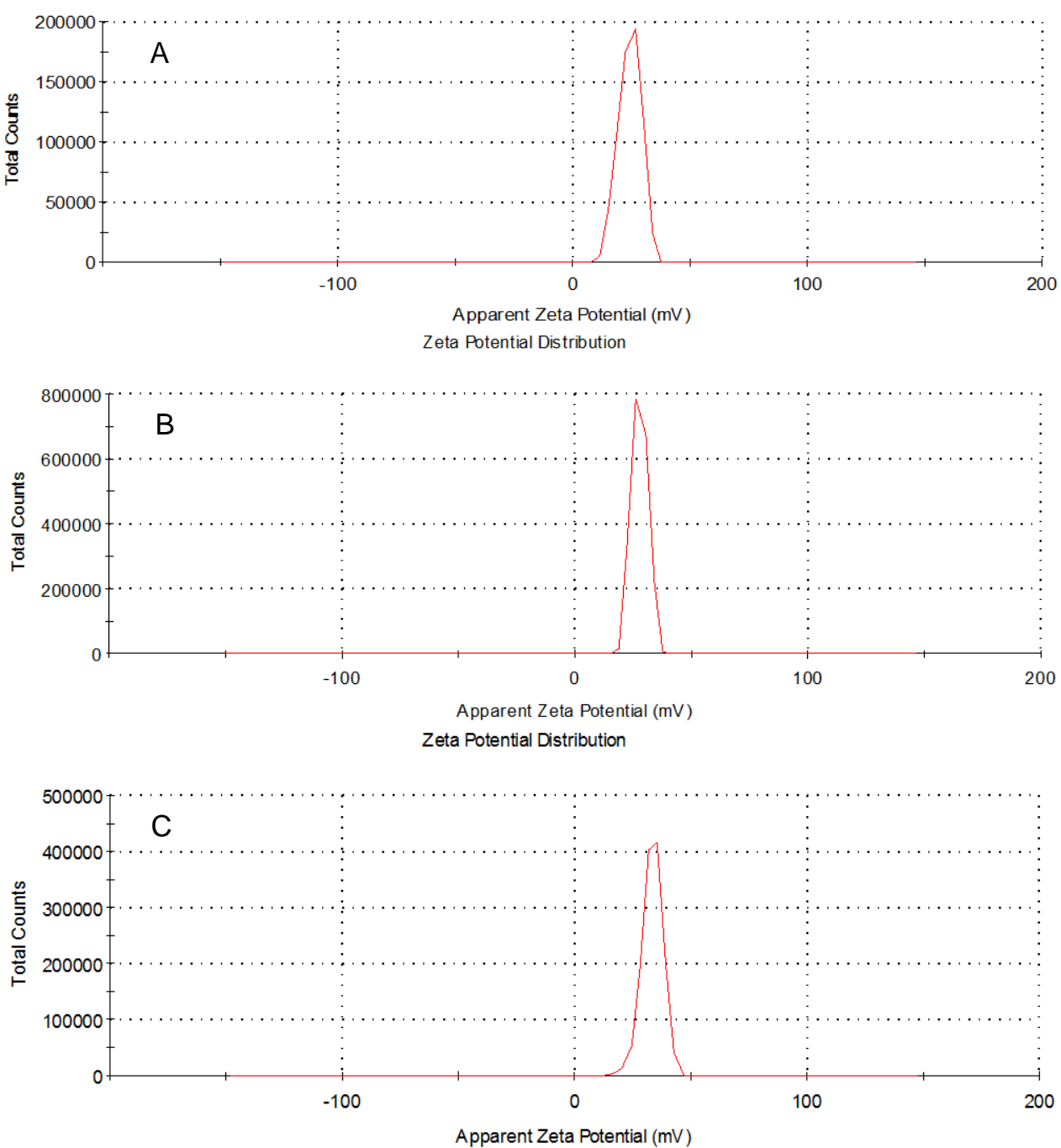

Fig. 3. Zeta potential of chitosan nano-particles.

(A): after 30 min milling (B): after 60 min milling process (C): after 90 min milling process

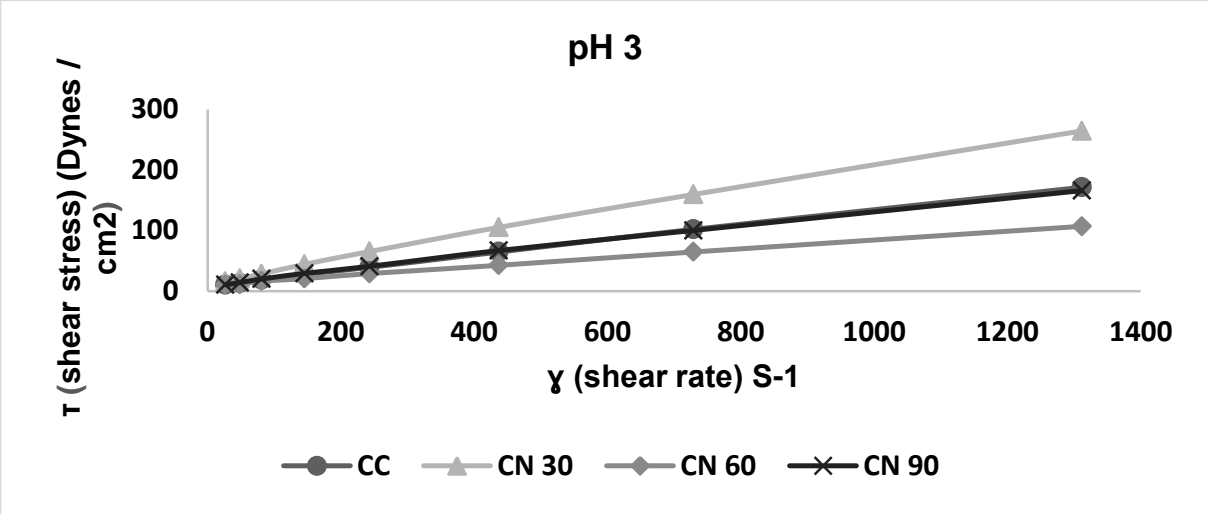

Fig. 4. Flow curves of the tested chitosan solution, at $\mathrm{pH} 3$.

AUJASCI, Arab Univ. J. Agric. Sci., 27(2), 2019 
As seen, From Figs. (5, 6 and 7), all flow curves showed shear stress values lower than those obtained at $\mathrm{pH} 3$. This decrease in shear stress values could be referred to the inhomogeneity of the chitosan suspension at these relatively high $\mathrm{pH}$ values and probably also to incompletet hydration of the particles coils resulting in coils with smaller hydration volume and leading to lower viscosity values. However, the same trend was found for the effect of milling time on the viscosity of the obtained solutions. Solutions of $30 \mathrm{~min}$. milled chitosan showed also higher viscosity values than those obtained after 60 and $90 \mathrm{~min}$. The lower viscosity of the long time milling in this case could be explained as discussed before.

The shear rate/ shear stress data of chitosan solutions were subjected to analysis according the power law equation as follows: $\sigma=K . \mathrm{Y}^{\mathrm{n}}$ equation (3) and the data are presented in Table (2). As seen, all flow curves of chitosan exhibited nonNewtonian behavior at the tested $\mathrm{pH}$ values. At $\mathrm{pH}$ 3 , the $n$-values were in the range of $0.62-0.74$. The non-Newtonianity of the chitosan solutions were increased as $\mathrm{pH}$ values were increased to 5, 7 and 9. The $\mathrm{n}$-values at this $\mathrm{pH}$ range, were decreased to the level $0.36-0.48$. On the other side, the values of consistency coefficient $(\mathrm{K})$ were in the range of 0.77-1.18 Dynes. $\mathrm{s}^{\mathrm{n}} / \mathrm{cm}^{2}$. at $\mathrm{pH}$ values higher than 3 , the reduction in $n$ value was accompanied by a remarkable increases in the $\mathrm{K}$ - value. Also, the k-values were increased to the level of 1.192.86 Dynes. $\mathrm{s}^{\mathrm{n}} / \mathrm{cm}^{2}$ at $\mathrm{pH}$ values of 5,7 and 9 . The differences in k- and n-values of chitosan solutions at different $\mathrm{pH}$ values could be balanced by calculating apparent viscosity at fixed shear rate for all tested chitosan solutions. For this purpose, a medium shear rate of $437 \mathrm{~s}^{-1}$ was selected and the resulted apparent viscosity values were calculated according to equation as follows: $(n a)=K .\left(437^{\mathrm{s}-1}\right)$ and given in Table (2). Chitosan solutions at $\mathrm{pH} 3$ showed the highest apparent viscosity values in the range 0.1-0.24 poise (10-24 centi posie). At higher $\mathrm{pH}$ values (5,7 and 9), the values of apparent viscosity were repressed to the level of 0.04 to 0.07 piose (4-7 Cp) in spite of increased k-values and decreased $n$-values at low $\mathrm{pH}$ values. Within data of viscosity values, crude chitosan and CN 90 showed the lowest $\mathrm{k}$-values at all tested $\mathrm{pH}$ values, while $\mathrm{CN} 30$ and $\mathrm{CN} 60$ showed the highest kvalues corresponding to the tested $\mathrm{pH}$ level. The higher k-values and apparent viscosity of CN 30 and CN 60 confirm the better solubility and dispersibility of chitosan molecules in the used solvents. As solubility and dispersibility are Known as a phenomenon of charge distribution and charge affinity between the solvent and the suspended material, it could be concluded that chitosan particles of CN 30 and CN 60 possess the most suitable charge on the surface of their particles facilitating the solubility and dispersibility of these particles in the solvents used. The obtained results agree with those of Lewandowska (2012). She reported that chitosan solution behave as non- Newtonian fluids. She reported apparent viscosity values at shear rate of $400-500 \mathrm{~S}^{-1}$ in the range of 0.01 0.015 Pa.s (0.1-0.15 poise), which agree with the results given in Table (2). The reported $n$ and $k-$ values in her work were 0.72-0.76 and 0.12-0.15, which also agree with the results obtained in Table (2) of the present work and proving the shear thinning behavior of chitosan solutions. The lower viscosity values of chitosan solutions at $\mathrm{pH}$ higher than 3 in the present work agree with the result obtained by Lewandowska (2012). She reported that apparent viscosity of chitosan chains depends on their conformation in aqueous acid solvent as well as on their electrostatic interaction with the solvent.

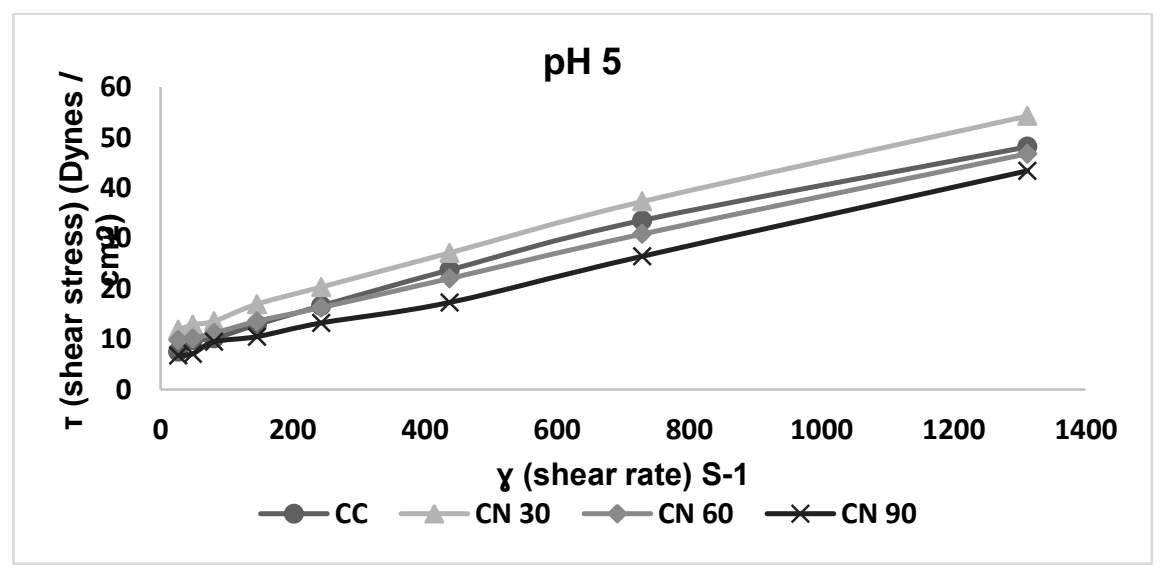

Fig. 5. Flow curves of the tested chitosan solution, at $\mathrm{pH} 5$. 
pH 7

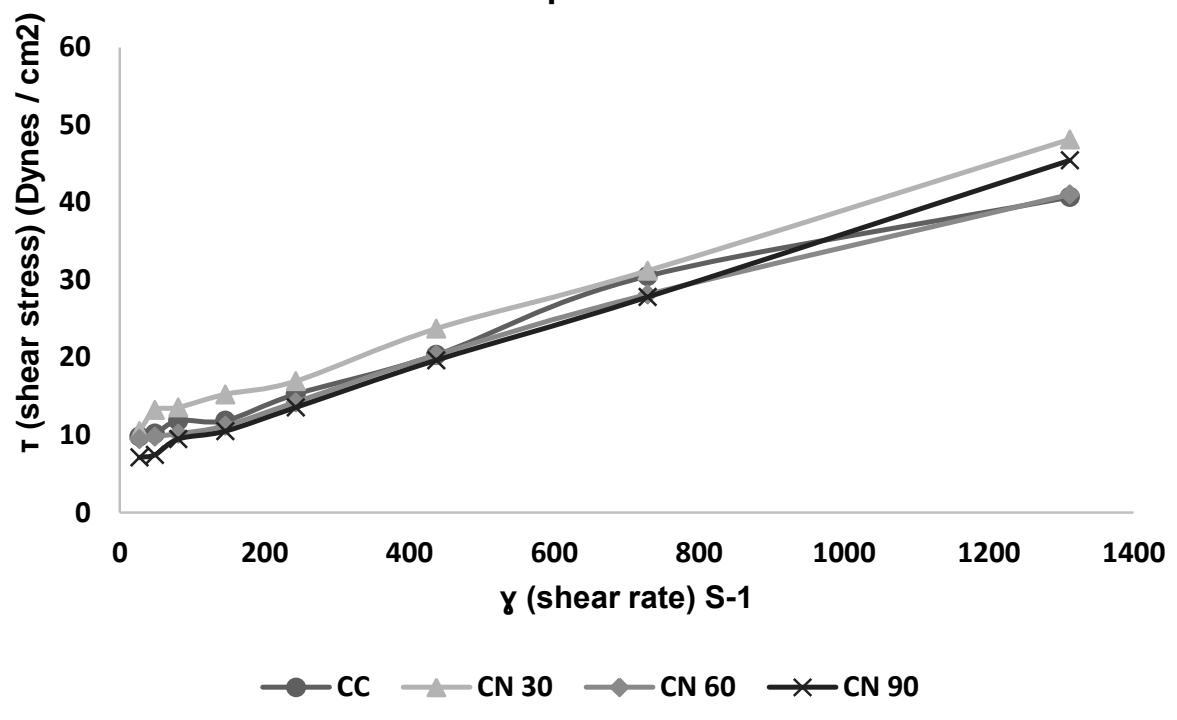

Fig. 6. Flow curves of the tested chitosan solution, at $\mathrm{pH} 7$.

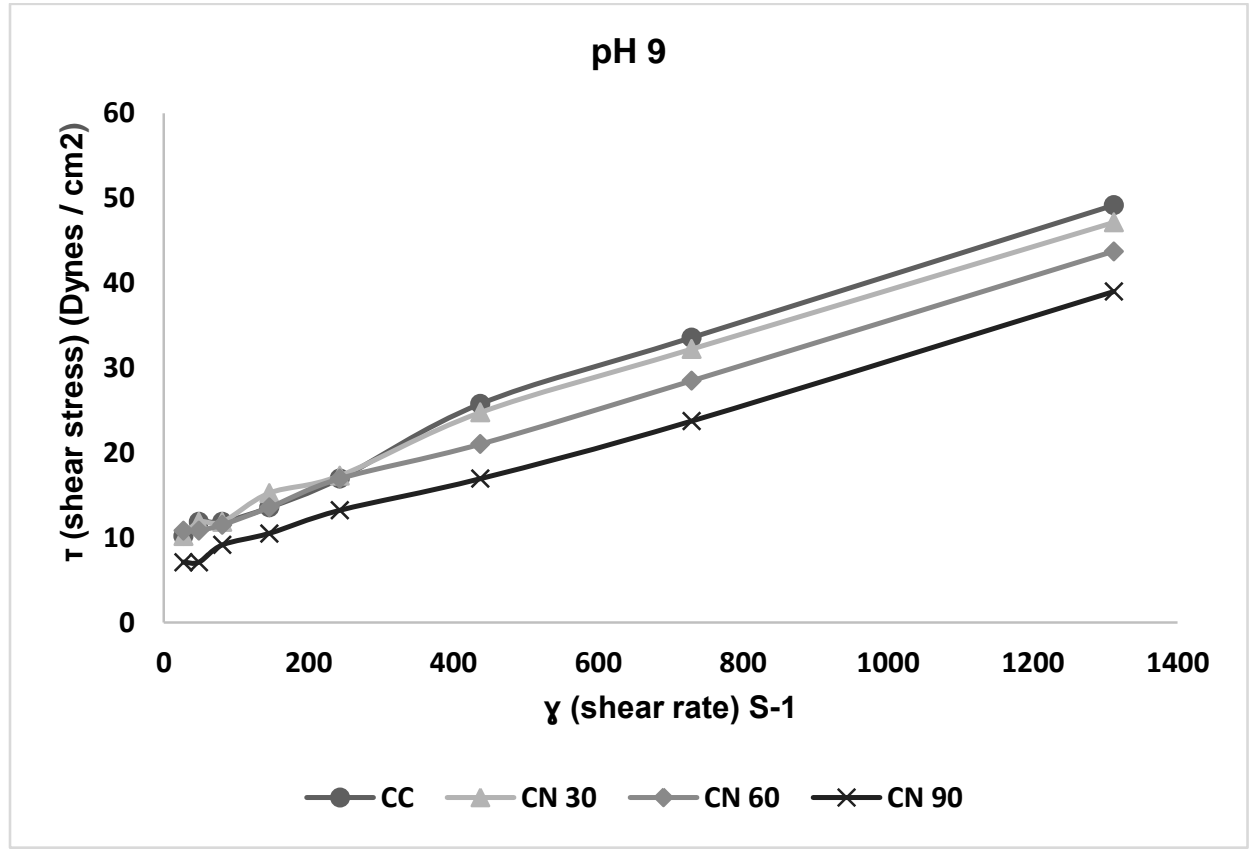

Fig. 7. Flow curves of the tested chitosan solution, at $\mathrm{pH} 9$. 
Table 2. Consistency coefficient $(K)$, flow behavior index $(n)$ and apparent viscosity (na) of crude chitosan and three different nanoparticle solutions at $\mathrm{pH} 3,5,7$ and 9 .

\begin{tabular}{|c|c|c|c|c|}
\hline Sample & $\begin{array}{c}K \\
\text { Dynes.s }{ }^{\mathrm{n}} / \mathrm{cm}^{2}\end{array}$ & $n$ & $\begin{array}{c}\text { na } \\
\text { (poise)at 437s- }{ }^{1}\end{array}$ & $\mathrm{R}^{2}$ \\
\hline Crud chitosan & 0.77 & 0.74 & 0.15 & 0.99 \\
\hline CN30 & 1.18 & 0.74 & 0.24 & 0.99 \\
\hline CN60 & 1.08 & 0.62 & 0.10 & 0.99 \\
\hline CN90 & 0.85 & 0.72 & .016 & 0.99 \\
\hline \multicolumn{5}{|c|}{ At pH 5} \\
\hline Crud chitosan & 1.39 & 0.48 & 0.06 & 0.99 \\
\hline CN30 & 2.69 & 0.39 & 0.07 & 0.99 \\
\hline CN60 & 2.08 & 0.40 & 0.06 & 0.99 \\
\hline CN90 & 1.20 & 0.47 & 0.05 & 0.99 \\
\hline \multicolumn{5}{|c|}{ At pH 7} \\
\hline Crud chitosan & 2.33 & 0.37 & 0.05 & 0.99 \\
\hline CN30 & 2.86 & 0.36 & 0.06 & 0.99 \\
\hline CN60 & 2.08 & 0.38 & 0.05 & 0.99 \\
\hline CN90 & 1.19 & 0.47 & 0.05 & 0.99 \\
\hline \multicolumn{5}{|c|}{ At pH 9} \\
\hline Crud chitosan & 2.21 & 0.41 & 0.06 & 0.99 \\
\hline CN30 & 2.40 & 0.39 & 0.06 & 0.99 \\
\hline CN60 & 2.65 & 0.36 & 0.05 & 0.99 \\
\hline CN90 & 1.39 & 0.43 & 0.04 & 0.99 \\
\hline
\end{tabular}

\section{CONCLUSION}

The obtained results revealed that ultrafine grinding could effectively pulverized the chitosan particles to nano-scale. The results of X-Ray Diffraction for Chitosan after 30,60 and 90 min milling process revealed that peaks were indicating the reduced crystalline nature of chitosan. Particle size of chitosan after 30, 60 and 90 min milling process was reduced to nanometer range from 250 to 600 $\mathrm{nm}$. With the importance of nanoparticles in almost all scientific disciplines and industries, this type of beads mill, which is capable of dispersing nanoparticles without chemical treatment, will have many applications. The solutions of chitosan blends behave as non-Newtonian fluids. Finally, the n-values are less than 1 , indicating the pseudo plastic behavior of chitosan solutions.

\section{REFERENCES}

Alishahi A. 2014. Antibacterial effect of chitosan nanoparticle loaded with nisin for the prolonged effect. J. of Food Safety 34, 111-118.
Anand M., Kalaivani R., Maruthupandy M., Kumaraguru A.K. and Suresh S. 2014. Extraction and characterization of chitosan from marine crab and squilla collected from the Gulf of Mannar Region, South India, J. of Food Safety, 34, 111-118.

Anand M., Sathyapriya P., Maruthupandy M. and Beevi A.H. 2018. Synthesis of chitosan nanoparticles by TPP and their potential mosquito larvicidal application. Frontiers in Laboratory Medicine 2, 72-78.

Badawy M. and Rabea E.I. 2011. A biopolymer chitosan and its derivatives as promising antimicrobial agents against plant pathogens and their applications in crop protection. Int. J. of Carbohydrate Chemistry, 2011, 1-29.

Bangun H., Tandiono S. and Arianto A. 2018. Preparation and evaluation of chitosantripolyphosphate nanoparticles suspension as an antibacterial agent. J. of Applied Pharmaceutical Sci., 8(12), 147-156.

Chang S.H., Lin H.T.V., Wu G.J. and Tsai G.J. 2015. PH Effects on solubility, zeta potential, and correlation between antibacterial activity and molecular weight of chitosan. Carbohydrate Polymers 134, 74-81. 
Daniel M.C. and Astruc D. 2004. Gold nanoparticles: assembly, supramolecular chemistry, quantum-size-related properties, and applications toward biology, catalysis, and nanotechnology. Chemical Reviews 104(1), 293-346.

De Paz C.L.E., Resin A., Howard K.A., Sutherland D.S. and Wejse P.L. 2011. Antimicrobial effect of chitosan nanoparticles on Streptococcus mutans. Applied Environmental Microbiology 77, 3892-3895.

Dounighi M.N., Eskandari R., MR A., Zolfagharian H., Sadeghi M.M.A. and Rezayat M. 2012. Preparation and in vitro characterization of chitosan nanoparticles containing Mesobuthus eupeus scorpion venom as an antigen delivery system. The J. of Venomous Animals and Toxins Including Tropical Diseases, 18(1), 44-52.

Dudhani A.R. and Kosaraju S.L. 2010. Bioadhesive chitosan nanoparticles: Preparation and characterization. Carbohydrate Polymers 81, 243-251.

Esquivel R., Juárez J., Almada M., Ibarra J. and Valdez M.A. 2015. Synthesis and Characterization of New Thiolated Chitosan Nanoparticles Obtained by lonic Gelation Method. Int. J. of Polymer Science, 2015, 1-18.

Fathi M., Martın A. and McClements D.J. 2014. Nanoencapsulation of food ingredients using carbohydrate based delivery systems. Trends in Food Science \& Technology 39, 18-39.

Gladwell N., Grimson M.J., Rahalkar R.R. and Richmond P. 1985. Rheological behavior of soy oil-water emulsions: dependence upon oil concentration. J. of Food Sci., 50, 440-443.

Grenha A. 2012. Chitosan nanoparticles: a survey of preparation methods. J. of Drug Targeting 20(4), 291-300.

Hosseini S.F., Zandi M., Rezaei M. and Farahmandghavi F. 2013. Two-step method for encapsulation of oregano essential oil in chitosan nanoparticles: preparation, characterization and in vitro release study. Carbohydr Polym. 5; 95(1), 50-56.

Inkyo M., Tahara T., Iwaki T., Iskandar F., Hogen C.J., Okuyama K. and Colloid J. 2006. Experimental investigation of nanoparticles dispersion by beads milling with centrifugal bead separation, J. Colloid Interf. Sci. 304, 535-540.

Islam M., Masum S.M., Rahman M., Molla A.I.M., Shaikh A.A. and Roy S.K.I. 2011. Preparation of chitosan from shrimp shell and investigation of its properties Int. J. Basic Appl. Sci., 11, 7780.
Joni I.M., Panatarani C. and Maulana D. 2015. Dispersion of fine phosphor particles by newly developed beads mill, Cite as: AIP Conference Proceedings 1712, $050019 \quad$ (2016); https://Doi.org/10.1063/1.4941902 Published Online: 24 February 2016

Kumar M.N.V.R. 2000. A review of chitin and chitosan applications. Reactive and Functional Polymers, 46(1), 1-27.

Lewandowska K. 2012. Rheological properties of chitosan blends with partially hydrolyzed polyacrylamide in different solvents. Progress on Chemistry and Application of Chitin and its Derivatives, 17, 53-62.

Li Du W., Niu S., Xu Y., Xu Z. and Fan C. 2009. Antibacterial activity of chitosan tripolyphosphate nanoparticles loaded with various metal ions. Carbohydrate Polymers 75, 385-389.

Li Q., Dunn E.T., Grandmaison E.W. and Goosen M.F.A. 1992. Applications and properties of chitosan. J. of Bioactive and Compatible Polymers, 7, 370-397.

Liu F., Antoniou J., Li Y., Yi J., Yokoyama W., Ma J. and Zhong F. 2015. Preparation of gelatin films incorporated with tea polyphenol nanoparticles for enhancing controlled-release antioxidant properties. J. Agric. Food Chem., 63, 3987-3995.

Ma Y., Liu P., Si C. and liu Z. 2010. Chitosan nanoparticles: preparation and application in antibacterial paper. J. of Macromolecular Sci., Part B: Physics, 49, 994-1001.

Ma Z., Maestu A.G. and Jeong K.C. 2017. A review application, mode of action, and in vivo activity of chitosan and its micro and nanoparticles as antimicrobial agents. Carbohydrate Polymers 176, 257-265.

Mao S., Shuai X., Unger F. and Simon M. 2004. The depolymerization of chitosan: effects on physicochemical and biological properties. Int. J. of Pharmaceutics 281, 45-54.

Paredes M.D., Rao M.A. and Bourne M.C. 1988. Rheological characterization of salad dressing. 1 - Steady shear, thixotropy and effect of temperature. J. of Text. Stud., 19, 274-258.

Pooja T.S., Sunil K.Y. and Pallavi S.P. 2014. Development and Characterization of Chitosan Nanoparticles Containing Erthromycin Estolate. Int. J. of Pharmaceutical Applications. 5(1), 1-7.

Pour Y.P., Atyabi F., Dinarvand R. and Farahani E.V. 2011. Preparation and comparison of chitosan nanoparticles with different degrees of glutathione thiolation. 19(5), 367-375. 
Qi L., Xu Z., Jiang X., Hu C. and Zou X. 2004. Preparation and antibacterial activity of chitosan nanoparticles. Carbohydrate Research 339, 2693-2700.

Rampino A., Borgogna M., Blasi P., Bellich B. and Cesàro A. 2013. Chitosan nanoparticles: Preparation, size evolution and stability. Int. J. of Pharmaceutics 455, 219-228.

Rhazi M., Desbrieres J., Tolaimate A., Alagui A. and Vottero P. 2004. Investigation of different natural sources of chitin: influence of the source and deacetylation process on the physicochemical characteristics of chitosan. Polymer Int. 49(4), 337-344.

Rochima E., Azhary S.Y., Pratama R.I., Panatarani C. and Joni I.M. 2017. Preparation and characterization of nanochitosan from crab shell waste by beads-milling method. Int. Conference on Food Sci. and Eng. 2016. IOP Conf. Series: Materials Sci. and Eng., 193, 012043.

Sano M., Hosoya O. and Taoka S. 1999. Relationship between solubility of chitosan in alcoholic solution and its gelation, Chemical and Pharmaceutical Bulletin, 47(7), 1044-1046.

Seo M.H., Lee S.Y., Chang Y.H. and Kwak H.S. 2009. Physicochemical, microbial and sensory properties of yogurt supplemented with nanopowdered chitosan during storage. J. of Dairy Sci., .92(12), 5907-5916.

Sozer N. and Kokini J.L. 2009. A review of nanotechnology and its applications in the food sector. Trends in Biotechnology 27(2), 8289.

Stoll V.S. and Blanchard J.S. 2009. Methods in enzymology, Vol. 463. In Bufferes: principles and practice Richard R.B. and Murray P.D. (Eds.), pp. 43-56. Academic Press.

Stoica R., Somoghi R. and Ion R.M. 2013. Preparation of chitosan - tripolyphosphate nanoparticles for the encapsulation of polyphenols extracted from rose hips. Digest J. of Nanomaterials and Biostructures 8(3), 955-963.

Sun Z., Shi C., Wang X., Fang Q. and Huang J. 2017. Synthesis, characterization, and antimicrobial activities of sulfonatedchitosan. Carbohydrate Polymers 155, 321-328.
Tang E.S.K., Huang M. and Lim L.Y. 2003. Ultrasonication of chitosan and chitosan nanoparticles. Int. J. of Pharmaceutics 265, 103-114.

Torres M.A., Beppu A.M., Santana C.C. and Arruda E.J. 2006. Viscoelastic properties of chitosan solutions and gels. Brazilian J. of Food Technology, 9(2), 101-108.

U.S. Food and Drug Administration 2001. Center for Food Safety and Applied Nutrition. Office of Premarket Approval. GRAS Notices received in 2001. http://vm.cfsan.fda.gov

Valerio S.G., Klein J.S., Rodrigues M.P. and Hertz P.F. 2013. High operational stability of invertase from Saccharomyces cerevisiae immobilized on chitosan nanoparticles. Carbohydr Polym. 92(1), 462-468.

Yao J., Cui B., Zhao X., Wang Y., Zeng Z., Sun C., Yang D., Liu G., Gao J. and Cui H. 2018. Preparation, characterization, and evaluation of azoxystrobin nanosuspension produced by wet media milling. Applied Nanoscience 8, 297307.

Zhang C., Ding Y., Ping Q. and Yu L. 2006. Novel chitosan-derived nanomaterials and their micelle-forming properties. J. of Agric. and Food Chem., 54(22), 8409-8416.

Zhang H. and Zhao Y. 2015. Preparation, characterization and evaluation of tea polyphenol- $\mathrm{Zn}$ complex loaded beta-chiitosan nanoparticles. Food Hydrocolloids. 48, 260-273.

Zhang W., Zhang J. and Xia W. 2012. The Preparation of chitosan nanoparticles by wet media milling. Int. J. of Food Sci. and Tech., 47, 2266-2272.

Zhang W., Zhang J., Jiang Q. and Xia W. 2013. The hypolipidemic activity of chitosan nanopowder prepared by ultrafine milling. Carbohydrate Polymers 95, 487- 491.

Zhou Z., S. Lin S., Yue T. and Lee Y. 2014. Adsorption of food dyes from aqueous solution by glutaraldhyde cross-linked magnetic chitosan nanoparticles. J. of Food Eng. 126, 133-141. 
مجلة اتحاد الجامعات العربية للعلوم الزراعية ، جامعة عين شمس ، القاهرة ، مصر

مجلد(27)، عدد(2)، 1527-1513، 2019

Website: http://ajs.journals.ekb.eg

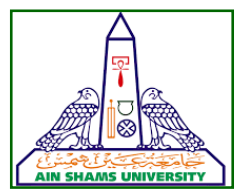

1527

تأثثر عملية الطدن وحجم الجزيئات على بعض الخصائص الفيزيائية والريولوجية للشيتوزان

[125]

$$
\begin{aligned}
& \text { إبراهيم أمين إبراهيم1" - حمدى مصطقى عبيد1 - ياسر فكري محد كثك } 1 \text { - } \\
& \text { عبد الفتاح عبد الكريم عبد الفتاح' - خالا فهمى محمود } 2
\end{aligned}
$$

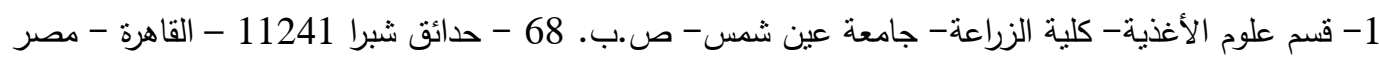

$$
\begin{aligned}
& \text { 2- قسم تكنولوجيا الأغذية - المركز القومي للبحوث - الدقي - الجيزة - مصر التعر }
\end{aligned}
$$

*Corresponding author: ibrahim amin89@agr.asu.edu.eg

Received 26 May, 2019

Accepted 2 July, 2019

القياسات الريولوجية من قانون الأس عند درجة 25

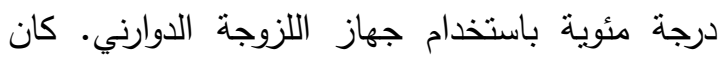

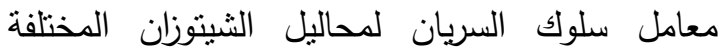

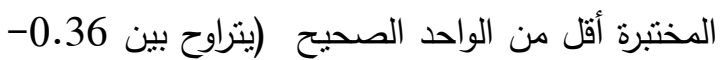
0.74) مما يدل على الطبيعة الثبه بلاستيكية لمحاليل

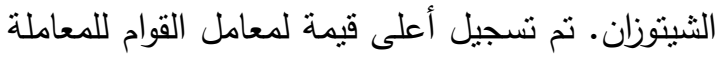

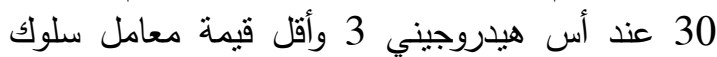

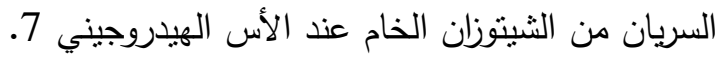

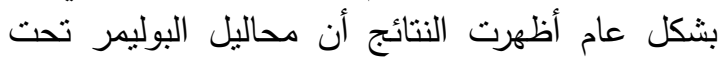

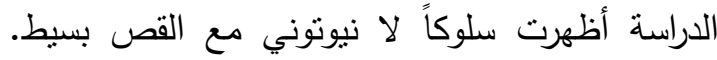

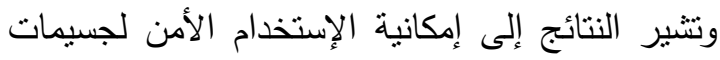
الثيتوزان النانومترية فى التطبيقات الغذائية نتيجة لزيادة الأنياة

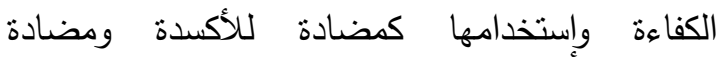

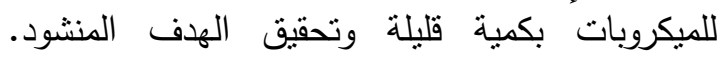

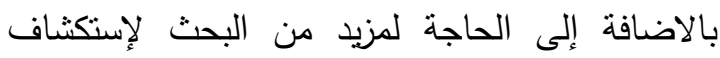

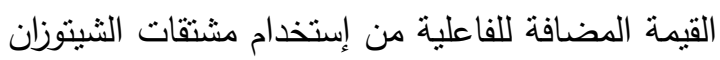
فى تحسين جودة وآمان بعض منتجات الأغذية.

الكلمات الدالة: الثيتوزان النانو، الطحن الرطب، النانوتكنولوجي، الخصائص الريولوجية والفيزيائية

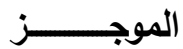

أجريت هذه الدراسة لتحضير جزيئات شينوزان

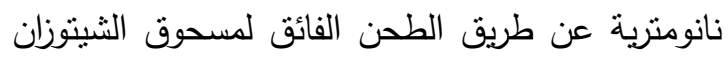
الخام عن طريق إستخدام مطحنة تحتوي على 130

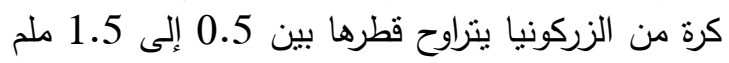
(75 كرة بقطر 0.5 ملم، 30 كرة كرة بقطر 1.5 كرة 1.5 ملم و25 كرة بقطر 1.5 ملم). بالإضافة إلى قلى قياس الخصائص الفيزيائية و الريولوجية لمحاليل الثيتوزان.

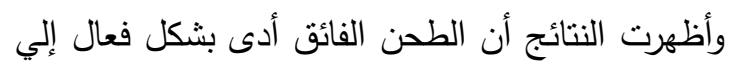

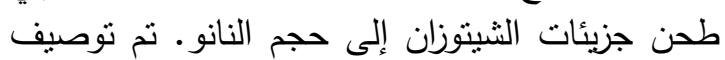

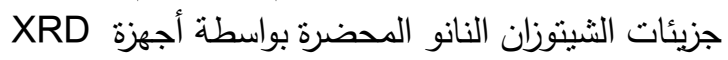

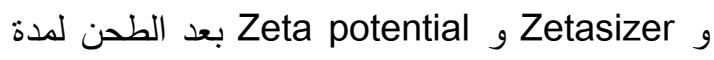
30 و 60 و 90 دقيقة. وكان حجم جزيئات الثيتوزان

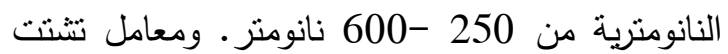
أقل من الواحد الصحيح وزادت شحنة الجسيمات الكهربائية إلى مستوى + 24 إلى 33 مللى فولت ثلت وأظهرت حيود الأشعة السينية كثافة منخفضة والثة

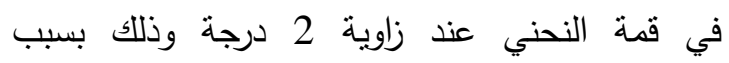
الثحنات فى الجزيئات البللورية وتم الحصول على درية 